\section{CONSIDERACIONES PARA LA DEFINICIÓN DE COINFECCIÓN EN CASOS DE LEPTOSPIROSIS}

\section{CONSIDERATIONS FOR THE DEFINITION OF CO-INFECTION IN LEPTOSPIROSIS CASES}

Stalin Vilcarromero ${ }^{1, a}$, Johan Marin ${ }^{2,3, a}$, Martin Casapia ${ }^{3, b}$

Sr. Editor. Con respecto a la carta publicada por HerreraPérez titulado «Leptospirosis y coinfecciones durante el Niño Costero en un Hospital del Norte Peruana», felicitamos a los autores por resaltar la importancia de leptospirosis y coinfecciones en escenarios de desastres naturales. Es interesante la descripción de 9 casos de coinfección. Sin embargo, hay omisión de información clínica y laboratorial de estos casos que nos permitan determinar una real coinfección (infección concomitante) o se trata simplemente de evidencia serológica de anticuerpos en estos pacientes.

En lugares en donde las condiciones ecológicas y sanitarias son favorables para la ocurrencia de casos de leptospirosis, estos pueden ser sintomáticos y agruparse en síndromes como: febril agudo indiferenciado (1), febril hemorrágico, febril Ictero-hemorrágico entre otros. Pero también pueden presentarse casos asintomáticos ${ }^{(2)}$ con resultados positivos persistentes en los exámenes de serología como el MAT (prueba de microaglutinación).

El MAT es considerado la prueba inmunológica de referencia que detecta anticuerpos aglutinantes contra cepas patogénicas de leptospira sp., pero no distingue si son "recientes" (IgM) o de "memoria" (IgG), y puede persistir positivo durante meses o años después de la infección ${ }^{(3-5)}$. Esta persistencia constituye una limitación importante en el diagnóstico serológico por MAT, especialmente en zonas endémicas, y que conlleva al requerimiento de muestras pareadas en momentos diferentes de la infección. Por estas razones, solamente con los datos cualitativos de la

\footnotetext{
1 Department of Medicine, Division of Infectious Disease, Stony Brook University. New York. EE.UU.

2 Médico Infectólogo. Departamento de Infectología, Hospital Regional de Loreto "Felipe Santiago Arriola Iglesias". Iquitos, Perú.

3 Facultad de Medicina "Rafael Donayre Rojas", Universidad Nacional de la Amazonía Peruana. Iquitos, Perú

a Médico Infectólogo; ${ }^{\text {b }}$ Médico Infectólogo, Magíster en Salud Pública.

Recibido: 17/04/2019 Aprobado: 15/05/2019 En línea:28/06/2019
}

Citar como: Vilcarromero S, Marin J, Casapia M. Consideraciones para la definición de coinfección en casos de leptospirosis. Rev Peru Med Exp Salud Publica. 2019;36(2):360-1. doi: http://dx.doi.org/10.17843/ rpmesp.2019.362.4466.
MAT, como ha sido descrito en el artículo, no es posible determinar el momento en el que se produjo la infección. Es necesario conocer los títulos de MAT en muestras de suero pareadas (fase aguda y convaleciente), obtenidas en momentos oportunos, y encontrar un cambio en ellos, de un resultado negativo a positivo (seroconversión) o un incremento de 4 veces los títulos para confirmar el diagnóstico ${ }^{(5)}$.

En el Perú, un solo título de MAT puede ayudar al diagnóstico, pero no es confiable y, requiere de títulos altos, que pueden variar según el escenario epidemiológico. Por ejemplo, un caso con gran sospecha clínica es considerado solamente como «caso probable» en la Amazonia Peruana, endémico para leptospirosis, o en la costa norte, afectado por fenómeno del «Niño Costero», con títulos de MAT iguales o menores a 1/800 o 1/200, respectivamente. Otra limitación, no mencionada por los autores, es que el diagnóstico de coinfección con dengue estuvo basado en los resultados de la prueba de Elisa IgM, sin considerar que estos anticuerpos IgM pueden persistir por un periodo de hasta 3 meses en pacientes convalecientes por dengue, y que además es probable una reacción serológica cruzada con otros arbovirus como el virus de Zika ${ }^{(6)}$. Una limitación final, está relacionada a la muestra (tamaño y selección de la muestra) y a la escaza información sobre la población de estudio que acude a este hospital, lo que hace que estos resultados sean considerados como un dato referencial cuando se reporta una proporción de coinfección, sin mayor relevancia epidemiológica.

En conclusión, de acuerdo con la información reportada existe poca evidencia laboratorial de una real coinfección y es posible una interpretación inadecuada de los exámenes serológicos.

Fuente de financiamiento: Este estudio fue autofinanciado

Conflictos de intereses: No hay conflicto de interés.

Descargo de Responsabilidad: Las opiniones y afirmaciones contenidas aquí son propias de los autores y no deben interpretarse como posición oficial o que reflejan la opinión del Ministerio de Salud del Perú o de la Universidad de Stony Brook, USA.

Contribuciones de autoría: SV, JM y MC participaron en la concepción, recolección de datos, análisis, preparación, revisión y aprobación del manuscrito.

\section{REFERENCIAS BIBLIOGRÁFICAS}

1. Reller ME, Wunder EA Jr., Miles JJ, Flom JE, Mayorga O, et al. Unsuspected leptospirosis is a cause of acute febrile illness in Nicaragua. PLoS Negl Trop Dis. 2014; 8: e2941. pmid:25058149 
2. Ganoza CA, Matthias MA, Saito M, Cespedes M, Gotuzzo E, Vinetz JM. Asymptomatic renal colonization of humans in the peruvian Amazon by Leptospira. PLoS Negl Trop Dis. 2010;4(2):e612. Epub 2010/02/27. pmid:20186328; PubMed Central PMCID: PMC2826405.

3. Adler B, Faine S. The antibodies involved in the human immune response to leptospiral infection. J Med Microbiol. 1978;11:387-400.

4. Romero EC, Caly CR, Yasuda PH. The persistence of leptospiral agglutinins titers in human sera diagnosed by the microscopic agglutination test. Rev Inst Med Trop São Paulo. 1998; $40: 183-184$.

5. Cumberland PC, Everard COR, Levett PN. Assessment of the efficacy of the IgM enzyme-linked immunosorbent assay (ELISA) and microscopic agglutination test (MAT) in the diagnosis of acute leptospirosis. Am J Trop Med Hyg. 1999;61:731-734.

6. Priyamvada L, Quicke KM, Hudson WH, Onlamoon N, Sewatanon J, Edupuganti $S$, et al. Human antibody responses after dengue virus infection are highly cross-reactive to Zika virus. Proc Natl Acad Sci U S A. 2016;113:7852-7. 10.1073/ pnas. 1607931113

Correspondencia: Stalin Vilcarromero.

Dirección: 141 Bergold Street, Brentwood, 11717, Nueva York, USA

Correo electrónico: stalinvil@gmail.com

\section{Escherichia coli PRODUCTOR DE BETALACTAMASAS DE ESPECTRO EXTENDIDO EN POLLOS PARA CONSUMO HUMANO}

\section{EXTENDED-SPECTRUM BETA LACTAMASE- PRODUCING Escherichia coli IN CHICKEN FOR HUMAN CONSUMPTION}

\author{
Lady Esther Huamán-Chacón 1,a, \\ Edgar Gonzales-Escalante 2,a
}

Sr. Editor. Durante años, la investigación sobre resistencia bacteriana estuvo centrada en bacterias aisladas de infecciones en humanos, en la actualidad existe gran interés por el estudio de bacterias de diferentes ecosistemas

\footnotetext{
1 Facultad de Tecnología Médica, Universidad Nacional Federico Villarreal. Lima, Perú.

2 Centro de Investigaciones Tecnológicas, Biomédicas y Medioambientales CITBM, Universidad Nacional Mayor de San Marcos. Lima, Perú.

a Tecnólogo médico

Recibido:30/09/2018 Aprobado: 27/03/2019 En línea: 28/06/2019
}

Citar como: Huamán-Chacón LE, Gonzales Escalante E. Escherichia coli productor de betalactamasas de espectro extendido en pollos para consumo humano. Rev Peru Med Exp Salud Publica. 2019;36(2):361-2. doi: http://dx.doi. org/10.17843/rpmesp.2019.362.3959. (animal, humano, alimentario, ambiente); estudiándose principalmente Escherichia coli y Enterococcus spp. por ser representantes de dos grupos bacterianos, los Gram negativos (GN) y Gram positivos (1).

Uno de los mecanismos de resistencia involucrado en GN es la producción de betalactamasas de espectro extendido (BLEE), que genera resistencia a muchos de los antibióticos betalactámicos de uso común, las cuales son transmitidas a través de plásmidos. Se ha descrito que un medio idóneo para que esta transmisión ocurra es la microbiota intestinal de humanos y animales, debido a que los antibióticos utilizados en el ámbito clínico y/o veterinario pueden ser excretados por vía entérica, estableciéndose de esta manera la presión selectiva a nivel intestinal, teniendo una gran importancia epidemiológica y evolutiva ${ }^{(2)}$.

Se ha considerado que ciertos alimentos de origen animal, principalmente en relación a las aves de corral, podrían ser fuente de transmisión de enzimas BLEE al hombre. Distintas publicaciones hacen referencia a la elevada presencia de Escherichia coli portadora de BLEE en las aves y principalmente en pollos ${ }^{(3-5)}$. Este aumento también se observa en aislamientos de origen clínico, lo que no necesariamente indica que exista una relación, pero evidencia que la resistencia bacteriana es un fenómeno global que está en aumento. El objetivo de este estudio fue determinar la presencia de Escherichia coli productora de BLEE en hisopado cloacal de pollos destinados al consumo humano.

Entre diciembre 2015 y abril 2016, se realizó el hisopado cloacal de 200 pollos vivos aparentemente sanos de dos centros de acopio de Lima, Perú. Para el aislamiento presuntivo de enterobacterias productoras de BLEE los hisopados se sembraron en agar MacConkey suplementado con $2 \mathrm{mg} / \mathrm{L}$ de cefotaxima, tomando una colonia lactosa positiva de aquellas placas donde hubo desarrollo, se identificaron por pruebas de bioquímica convencional, la detección fenotípica de BLEE se realizó mediante el método de sinergia del doble disco y la susceptibilidad antimicrobiana se determinó por el método de disco difusión de acuerdo a las recomendaciones del CLSI ${ }^{(6)}$. De los 200 hisopados cloacales, se detectaron 163 (85,5\%) Escherichia coli productoras de BLEE. El perfil de susceptibilidad se muestra en la figura 1.

Estudios con valores similares al presente reporte fueron hallados por Abreu et al ${ }^{(3)}$ en España, encontrando 86,6\% de Escherichia coli productora de BLEE. Así mismo Dierick et al, describieron un aumento de la prevalencia de Escherichia coli productora de BLEE en el tracto gastrointestinal de animales destinados al consumo, en especial pollos, pasando del 3\% en 2003 al 15\% en 2008 